\title{
Rupture of vasa vasorum and intramural hematoma of the aorta: a changing paradigm
}

Ruptura dos vasa vasorum e hematoma intramural da aorta: um paradigma em mudança

Jan Janzen

J. vasc. bras. vol.9 no.2 Porto Alegre June 2010

Dear ladies and gentlemen

I would like to congratulate Adamastor Humberto Pereira for his excellent review about rupture of vasa vasorum in 2010.

From the vascular histopathologist standpoint of view it is worth emphasising the role of vasa vasorum in acute dissection with and/or without aneurysms.

We found lightmicroscipally in 46 of 171 cases a rupture of vasa vasorum as the cause of dissection (Figure 1 and 2) ${ }^{1,2}$.

Furthermore I would like to remark that vasa vasorum in aneurysms of the aorta ascendens presenting a wide morphological spectrum. In atherosclerotic aneurysms nonstenotic vasa vasorum were observed. In contrast to these findings non-atherosclerotic aneurysms showed concentric and excentric stenosis causing leiomyomatous hyperplasia ${ }^{3}$.

\section{References}

1. Janzen J. Ätiologie von 171 Aneurysmata der Aorta ascendens. Perfusion 2007;20:256-62.

2. Janzen J, Schmidli J. Marfan, Stary, Vuong und andere. 7. Dreiländertagung, Gefässchirurgie, Berlin 7-11. September 2010.

3. Janzen J, Aebert H, Ziemer G, Guyot H, Bültmann B. Morphologische Aspekte der Vasa vasorum in Aneurysmen der Aorta ascendens. Perfusion. 2003;16:394-9.

\section{Correspondência}

Dr. Med. Jan Janzen, MPhil

VASCPATH

Bern, Switzerland

E-mail:info@janlab.ch

\section{RESPOSTA DO AUTOR}

Caro Doutor Jan Jansen,

Acuso o recebimento da carta enviada ao Jornal Vascular Brasileiro (JVB) sobre nosso artigo „Ruptura dos vasa vasorum e hematoma intramural da aorta: um paradigma em mudança" Agradecemos os comentários e as

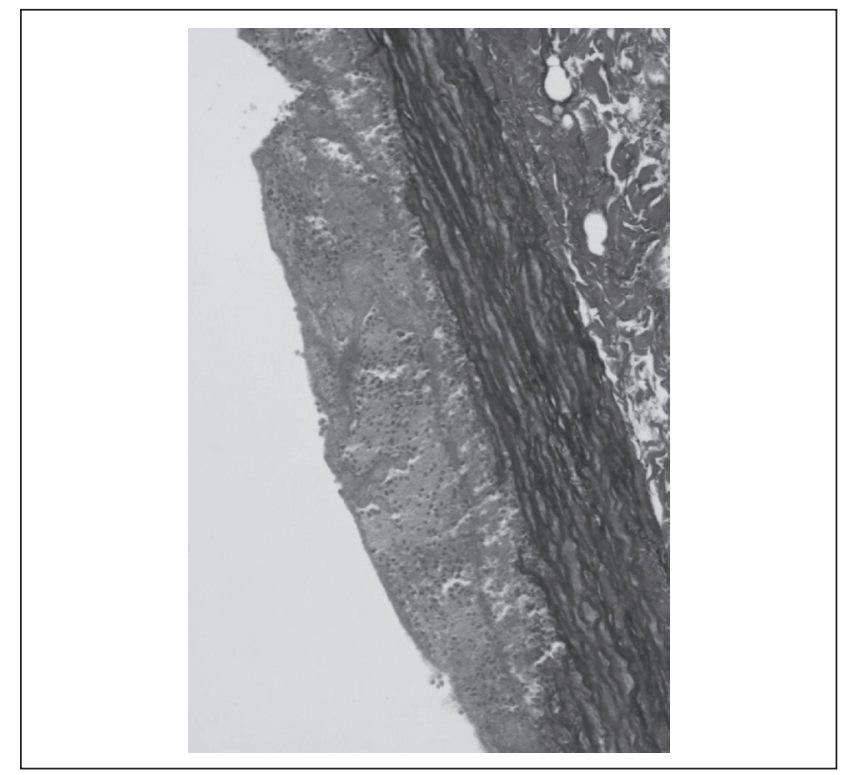

Figure 1- Acute aortic dissection



Figure 2 - Acute aortic dissection presenting rupture of vasa vasorum 
excelentes imagens mostrando a ruptura dos vasa vasorum em um espécime de dissecção da aorta.

A pergunta que se impõe quando observamos esses achados é se a ruptura desses vasos ocorre primariamente como causa da dissecção ou se se trata de um fenômeno secundário ao desarranjo das lamelas da túnica média. Alterações genéticas ou adquiridas certamente estão envolvidas. Talvez um dos fatores mais importantes na desestruturação da túnica média seja a hipertensão arterial. Essa condição leva à obstrução dos vasa vasorum, provocando uma isquemia relativa das porções mais externas da túnica média. Como consequência, ocorre um endurecimento dessa porção mais externa e cria assim uma situação em que a parede aórtica passa a apresentar duas regiões, com características elasto-mecânicas completamente diferentes. Essa é uma explicação aceitável para justificar porque a luz verdadeira é sempre comprimida na dissecção pelas porções externas mais rígidas. Ainda mais, como o estresse na parede aórtica é maior na túnica média, não seria de se estranhar a ruptura das lamelas na interface dessas duas regiões com subsequente ruptura dos vasa vasorum.

Uma outra pergunta que nos intriga é se a ruptura da íntima ocorre sempre a partir da luz para a túnica média. Novamente lembramos que já está bem estabelecido nos modelos experimentais que o estresse maior ocorre na média; então, por que não imaginar que, pelo menos em alguns casos, a ruptura possa se fazer no sentido inverso? Isso explicaria também porque alguns hematomas intramurais evoluem para dissecção clássica.

Em resumo: as perguntas sem resposta são muitas e os conhecimentos sobre a fisiopatologia da dissecção aórtica ainda se apoiam em fundamentos muito frágeis.

\section{Sinceramente,}

Adamastor H Pereira MD, PHD

Universidade Federal do Rio Grande do Sul 